\title{
An Empirical Study on Factors Influencing Business Students' Choice of Specialization with Reference to Nizwa College of Technology, Oman
}

\author{
Essam Hussain Al-Lawati ${ }^{1}$, Renjith Kumar. $\mathrm{R}^{2}$, Radhakrishnan Subramaniam ${ }^{2}$ \\ ${ }^{1}$ Head of Department of Business Studies, Nizwa College of Technology, P.B. 477, P.C. 611, Nizwa, Sultanate of \\ Oman \\ ${ }^{2}$ Lecturer in Marketing, Department of Business Studies, Nizwa College of Technology, P.B. 477, P.C. 611, \\ Nizwa, Sultanate of Oman \\ Correspondence: Essam Hussain Al-Lawati, Head of Department of Business Studies, Nizwa College of \\ Technology, P.B. 477, P.C. 611, Nizwa, Sultanate of Oman.
}

Received: July 24, 2017

doi:10.5539/ibr.v10n9p177
Accepted: August 17, 2017

Online Published: August 21, 2017

URL: https://doi.org/10.5539/ibr.v10n9p177

\begin{abstract}
The academic specialization chosen by students is of crucial importance for their future career and therefore they should have access to appropriate information and guidance that would help facilitate a more optimal decision. This study aims to identify the variables that influence business students to choose their specialization. A sample of 163 business students from Nizwa College of Technology, Sultanate of Oman, is selected for the study. Factor analysis and multiple regression analysis are used for analysis. The most important variable that influences the students' choice of specialization is the variable 'Liking and preference of specialization' (X2) with the highest mean. The factor analysis analysis output reveals the five sub-scales that influence students' choice of specialization; Preference and dissonance post choice, Self and Peer influence, Nature of marketing specialization, Gender and specialization choice, Convenience and career. College orientation on specialisation (X5) is a significant factor that influences the students to advice their juniors to make the first choice of specialisation viz. HRM (63\%), Accounting (32\%) and Marketing (5\%).
\end{abstract}

Keywords: preference and dissonance post choice, self and peer influence, nature of the specialization, gender and specialization choice, convenience and career

\section{Introduction}

Worldwide, university students are in transition to the world of work. For them, a careful choice of their career is more important than any other groups of students as they need to reflect on their chosen majors, interests, ability and consider what is available to work. Studies on the career choice attest that undergraduate students choose their prospective careers as a last resort (Bennell, 2004; Nwalo \& Issa, 2008). As a result, the majority of students are not suited for their careers, and, as such, they usually find themselves in careers that do not satisfy their needs and interests (Nwalo \& Issa, 2008).This implies that the majority of graduates will end up working in careers they were not formally educated. A few graduates who decide to join a career will probably not stay long. Consequently, their work performance, and in turn, national development will be affected. Oman is one of the developing economies among GCC countries (World Economic Outlook, 2016). Higher Educational Institutions (HEI) in Oman offer programs and courses based on the need of the market. In different governance, programs and courses are offered to its nationals through seven Colleges of Technology.

\section{Need and Scope of the Study}

The industry is witnessing a huge potential for various marketing openings that are currently available in various sectors. However, Omani marketing graduates are very scarce in the labor market. Carson (1990) stated that, even firms do not concentrate on marketing function as against other functional areas of business viz. accounting and finance. Irrespective of the size of the business, all entrepreneurs face problem in terms of understanding the concepts and philosophies of marketing (Al-Lawati 2017). Therefore, the Colleges of Technology opines that marketing workforce with employable skills need to be developed. To that effect, a study is to be conducted to understand the perception with reference to marketing specialization among student community. A study of this 
nature is imperative to throw light on the psychological and personal choice of the students in selecting a specialization during their program in business studies.

\section{Statement of the Problem}

It is observed that business students in Nizwa College of Technology prefer Human Resources Management and Accounting specialisation compared to Marketing when they move to higher levels. The college has not offered all the specializations simultaneously from 2004 for students according to their liking and preferences. Only Human Resources Management and Accounting Specializations were offered since September 2006 and later on according to the labor market requirements other specializations viz. E-Business and Marketing were offered in September 2009. Therefore, all the students entered into either Human Resources Management specialization or Accounting specialization. Later on, when E- Business and Marketing specializations were offered, it was found by the administration of the college that most of the students opted Human Resources Management Specialization and Accounting specialization and only a minor percentage of students opted E-Business and Marketing specialization. E - Business Specialization was suspended since September 2014. Therefore, the criteria for offering a particular specialization were arrived as per the CGPA secured by the student community. The total number of students that were likely to move to Diploma second year were divided equally into the number of specializations offered by the department, which was not student centered but system centered. This practice over the years had a cumulative effect of creating a negative perception in the minds of the students' community with regards to marketing specialization. Over the last two years the flow of students into higher levels in Accounting and Human Resources Management specialization are relatively higher than into Marketing specialization. There is a need to know the underlying reasons behind this trend. Therefore this study is conducted to identify the perception variables that influence students when they choose their specialization.

\section{Review of Literature}

It is evident that individuals possess unique characteristics, values, needs and personalities, which result in different career aspirations and expectations (Mubiana, 2010; Datu, 2012). To pursue the right career, they need to make a wise and careful choice. This means that people need to have reasons for preferring one career over another. The reasons should be accompanied by, among others, enough occupational information relating to the respective career choice (Kidd, 2009). The available studies have showed that for students to join their careers a careful analysis of what has influenced their choices is imperative (Wang \& Fwu, 2001). This implies that there is a close relationship between the reasons for an individual's career choice and his or her decision to join it. Empirical studies in Tanzania focused on determinants of career choice (Cosmas, 2010; Mbilinyi, 2012) but paid less attention to the relationship between what are the reasons behind the choice and students' decisions to join their prospective careers. These studies targeted at secondary education level were little known among uni versity students who are in the transition from colleges to the world of work. Career selection decision making process is one of the key elements in an individual's life (Alberts, Mbalo \& Ackermann, 2003). There exist numerous problems encountered by students in their process of career selection (Olamide and Olawaiye, 2013). Wrong career selection opens the door for lifelong consequences (Mashige and Oduntan, 2011). The results of a quantitative study conducted in central Pennsylvania by taking rural young adults and adolescents indicated that influence exerted by an individual's family, society, state of economy, their interpretation of better job and financial constraints were major reasons that can influence their career selection (Ferry, 2006). A study conducted in South Africa revealed that the financial factors have an impact on career choices of students (Abrahams, Jano \& Van, 2015). Zhang (2007) concluded that personal liking of an individual towards a particular subject contributes in his career selection decision. Shertzer and Stone (2003) found that interest depicted by students in some subjects will mostly lead to the better examination performance and selection of a profession in the same direction. Edward and Quinter (2012) disclosed that an individual's inclination towards a particular field or subject, its preference for a particular job and match between his personality and selected professions is an important factor contributing in career path. Livanos and Pouliakas (2009) suggested that promotion of gender equality should pay closer attention to the educational choices of men and women prior to entry into the labor market. Rebecca, Nyaga \& Benard (2016) conducted a study on 399 students in Kenya which resulted in that there is a relationship between personality types, and career choice. Most of the students were satisfied with the course they selected before entering the university that indicates that suitable career choice for students would improve satisfaction and success in their course of study and future employment. The distribution of students among higher education institutions is of great interest since the competition for induction into specific academic fields, mainly those which enjoy social recognition and higher wages in the labor market, is more intense (Gouvias, 1998; Psacharopoulos \& Papakonstantinou, 2005; Saiti \& Prokopiadou, 2008; Sianou-Kyrgiou \& Tsiplakides, 2009; Sianou-Kyrgiou, 2010; Tsakloglou \& Antoninis 1999). A study on 
individuals' abilities in different sciences among final year students in two universities of Oregon in the U.S.A., showed that the distribution of individuals in different fields is closely linked to their abilities (Paglin \& Rufolo, 1990). Zafar (2009) used primary source data from second year students of Northwestern Uni versity to analyze their preferences and professional expectations regarding their choice of scientific field. Results showed that preferences (intrinsic motives) are a significant determinant factor that influences the choice of scientific field. McCorkle, Payan, Reardon \& Kling, (2007) conducted a study to understand underlying reasons as to why marketing students have a better appreciation of the importance of creativity than other business students, while they do not appear to be more creative than other business students or nonbusiness students.

\section{Objectives of the Study}

1. To determine the major contributing variables that influences business students to choose their specialization.

2. To develop a model of variables that creates impact on the selection of specialization by the students

3. To assess the factor that influences students to advise their juniors in terms of first, second and third choice.

\section{Research Methodology}

The study is conducted among the Business students in Nizwa College of Technology, Sultanate of Oman. The sampling frame comprise of 434 Students in Business Studies Department who are from Diploma second year, Advanced Diploma and B.Tech levels pursuing HRM and Accounting specializations. Students pursuing marketing specialization were excluded from the study as this study is likely to create a negative perception in terms of the prospects of marketing specialization in the minds of young students. A sample size of 205 from the sampling frame is taken for the study (Krejcie and Morgan, 1970). Proportionate stratified sampling method is used for selecting the sample respondents. The period of the study was during November 2016 to January 2017. Primary data is collected using a structured questionnaire. The questionnaire was de veloped by the researchers keeping in mind the level of students in the program. The questionnaire comprises of three sections viz, personal details of the respondents, 15 statements on a five point psychometric Likert learning scale used for educational purpose and a set of open ended questions. A pilot study is conducted to check the validity and fix errors in the instrument. The reliability of the instrument is calculated and the Cronbach's alpha value is 0.74 . The response rate is $80 \%$ and therefore 163 filled responses are taken for this study. Participants were subject to a comfort zone in their class rooms and they were not embarrassed or subject to any mental stress. Factor analysis is used to reduce the factors and identify the core variables and multiple regression method is used to find the relevant variable that creates an impact on the choice of specialization.

\section{Anal ysis and Discussions}

The demographic profile of the sample respondents are briefly explained as follows. $83 \%$ of the respondents are females and remaining $17 \%$ are male students. Comparing the age group of the students, $31 \%$ belong to the age group of $19-20$ years. $54 \%$ of the respondents are in the age group of $21-22$ years. Remaining $15 \%$ of the students belong to the age group 23-24 years. The sample is collected from students in various levels of education. $13 \%$ of the students are in mixed level, $49 \%$ of the students are in second year diploma and $22 \%$ of the students are in Advanced diploma level. 16\% of the students are in B Tech level. Among the sample respondents, 53\% of the students are from Human Resources specialization, 29\% from Accounting specialization and remaining $18 \%$ of the students are in the mixed level.

Table 1. Descriptive Statistics (Specialization)

\begin{tabular}{clcc}
\hline Sl. No & Factors & Mean & Std. Deviation \\
\hline 1 & Self-preferred (X1) & 4.0061 & 1.07438 \\
2 & Like the specialization (X2) & 4.1779 & 1.12722 \\
3 & Job opportunities (X3) & 4.0675 & 1.05485 \\
4 & Feel now as Inappropriate (X4) & 4.0184 & 1.04511 \\
5 & College oriented to choose (X5) & 3.4663 & 1.14548 \\
6 & Easy to study (X6) & 3.0613 & 1.02254 \\
7 & HRM and Accounting appropriate for females (X7) & 3.6319 & 1.24701 \\
8 & Marketing needs more field work and travel (X8) & 3.1227 & 1.05861 \\
9 & Marketing jobs are for expatriates (X9) & 2.9264 & 1.06897 \\
10 & Students with high CGPA deserve HRM or Accounting (X10) & 3.4356 & 1.25726 \\
11 & Marketing is inferior to other specializations (X11) & 3.0798 & 1.03627 \\
12 & Family advice (X12) & 3.5644 & 1.23247 \\
13 & Friend's and seniors advice (X13) & 3.1350 & 1.28388 \\
14 & Evaluated the possibilities myself (X14) & 3.7975 & 1.08957 \\
15 & More jobs available for marketing (X15) & 3.3374 & 1.17179 \\
\hline
\end{tabular}


The first output from the factor analysis is the table of descriptive statistics of the variables under investigation. This is shown in table 1 . The mean and standard deviation of the 163 respondents who participated in the survey are given. From the mean values, it can be concluded that the most important variable that influences the students is their liking towards specialization and are not influenced by any one. If has the highest mean of 4.17. The second most important factor that influences students of choose specialization is the perception of getting job offers with an average score of 4.06 .

Table 2. Correlation Matrixa

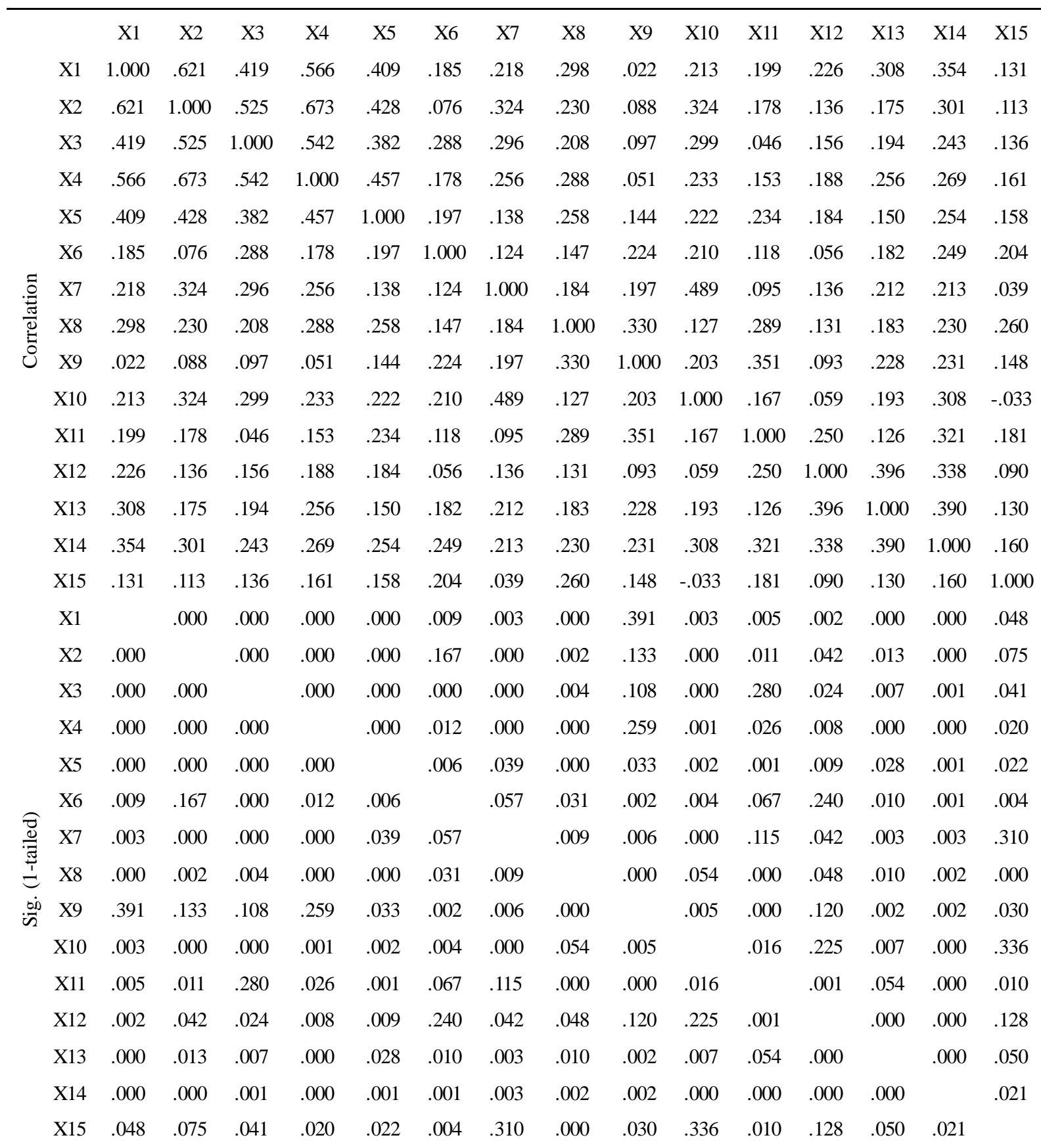

a. Determinant $=.016$

SPSS output shows the abridged version of R-matrix. The top half of table 2 contains the Pearson correlation coefficient between all pairs of questions whereas the bottom half contains the one-tailed significance of these coefficients. By scanning the significance values it is clear that majority of the values are less than 0.05 and no values are greater than 0.9. Hence, there is no need to eliminate any variable. There is no problem of multicollinearity. Thus all the questions correlate fairly well and none of the correlation coefficients are particularly large. Therefore, there is no need to consider eliminating any questions at this stage. 
Table 3. KMO and Bartlett's Test

\begin{tabular}{llc}
\hline Kaiser-Meyer-Olkin Measure of Sampling Adequacy & & .815 \\
Bartlett's Test of Sphericity & Approx. Chi-Square & 643.489 \\
& Df & 105 \\
& Sig. & .000 \\
\hline
\end{tabular}

Table 3 shows the important parts of SPSS output; Kaiser-Meyer-Olkin Measure of Sampling Adequacy and Bartlett's Test of Sphericity. The KMO statistic varies between 0 and 1 . A value of 0 indicate that the sum of the partial correlations is large relative to the sum of correlations, indicating diffusion in the pattern of correlations. Hence factor analysis is inappropriate. A value close to 1 indicates that patterns of correlations are relatively compact and so factor analysis should yield distinct and reliable results. Kaiser (1974) recommends accepting values greater than 0.5 as acceptable. Values between 0.5 and 0.7 are mediocre, values between 0.7 and 0.8 are good, values between 0.8 and 0.9 are great and values above 0.9 are superb (Hutcheson \& Sofroniou, 1999). For this data the value is 0.81 which falls into the range of great and therefore factor analysis is appropriate for this data.

Bartlett's measure tests the null hypothesis that the original correlation matrix is an identity matrix. For factor analysis to work, there must be some relationships and if R-matrix is an identity matrix, then all correlation coefficients would be zero. A significance test tells that the R-matrix is not an identity matrix, therefore, there are some relationships between the variables. In this data, Bartlett's test is highly significant $(0.000)$ and therefore the factor analysis is appropriate.

\section{Factor Extraction}

The SPSS output in table no 4 lists the eigenvalues associated with each linear factor before extraction, after extraction and after rotation. Before extraction, SPSS has identified 15 linear components within the data set. The eigenvalues associated with each factor represent the variance explained by that particular linear component and SPSS also displays the eigenvalues in terms of percentage of variance explained. So factor 1 (Self-preferred) explains $29.26 \%$ of total variance. SPSS extracts all the factors with eigenvalues greater than one that leaves with five factors. The eigenvalues associated with these factors are displayed with the percentage of variance in the column labelled. The values in the extracted sum of squared loadings are the same as the values before extraction, except that the values for the discarded factors (after five factors) are ignored. In the rotation sums of squared loadings, the eigenvalues of the factors after rotation are displayed. Before rotation factor 1 accounted for more variance $(29.26 \%$ ) than the remaining four factors. However, after extraction it accounts for only $3.58 \%$ of variance. Similarly factor 2 'liking towards specialization' (X2) accounts for $10.94 \%$ of variance. Thus $63.5 \%$ of the cumulative variance is contributed by the first five variables (X1, X2, X3, X4 and X5) and remaining factors contribute $36.5 \%$ of cumulative variance.

Table 4. Total Variance Explained

\begin{tabular}{|c|c|c|c|c|c|c|c|}
\hline \multirow[t]{2}{*}{ Component } & \multicolumn{3}{|c|}{ Initial Eigenvalues } & \multicolumn{3}{|c|}{ Extraction Sums of Squared Loadings } & \multirow{2}{*}{$\begin{array}{c}\begin{array}{c}\text { Rotation Sums } \\
\text { of Squared } \\
\text { Loadings }\end{array} \\
\text { Total }\end{array}$} \\
\hline & Total & $\begin{array}{c}\% \text { of } \\
\text { Variance }\end{array}$ & Cumulative $\%$ & Total & $\begin{array}{c}\% \text { of } \\
\text { Variance }\end{array}$ & Cumulative \% & \\
\hline $\mathrm{X} 1$ & 4.389 & 29.261 & 29.261 & 4.389 & 29.261 & 29.261 & 3.585 \\
\hline $\mathrm{X} 2$ & 1.642 & 10.948 & 40.208 & 1.642 & 10.948 & 40.208 & 2.101 \\
\hline $\mathrm{X} 3$ & 1.289 & 8.592 & 48.801 & 1.289 & 8.592 & 48.801 & 1.885 \\
\hline $\mathrm{X} 4$ & 1.194 & 7.960 & 56.761 & 1.194 & 7.960 & 56.761 & 2.319 \\
\hline X5 & 1.010 & 6.734 & 63.495 & 1.010 & 6.734 & 63.495 & 1.635 \\
\hline X6 & .839 & 5.594 & 69.089 & & & & \\
\hline X7 & .735 & 4.901 & 73.989 & & & & \\
\hline $\mathrm{X} 8$ & .674 & 4.493 & 78.482 & & & & \\
\hline X9 & .604 & 4.024 & 82.506 & & & & \\
\hline $\mathrm{X} 10$ & .585 & 3.898 & 86.404 & & & & \\
\hline X11 & .531 & 3.540 & 89.944 & & & & \\
\hline $\mathrm{X} 12$ & .460 & 3.067 & 93.011 & & & & \\
\hline $\mathrm{X} 13$ & .403 & 2.688 & 95.699 & & & & \\
\hline $\mathrm{X} 14$ & .384 & 2.559 & 98.259 & & & & \\
\hline $\mathrm{X} 15$ & .261 & 1.741 & 100.000 & & & & \\
\hline
\end{tabular}




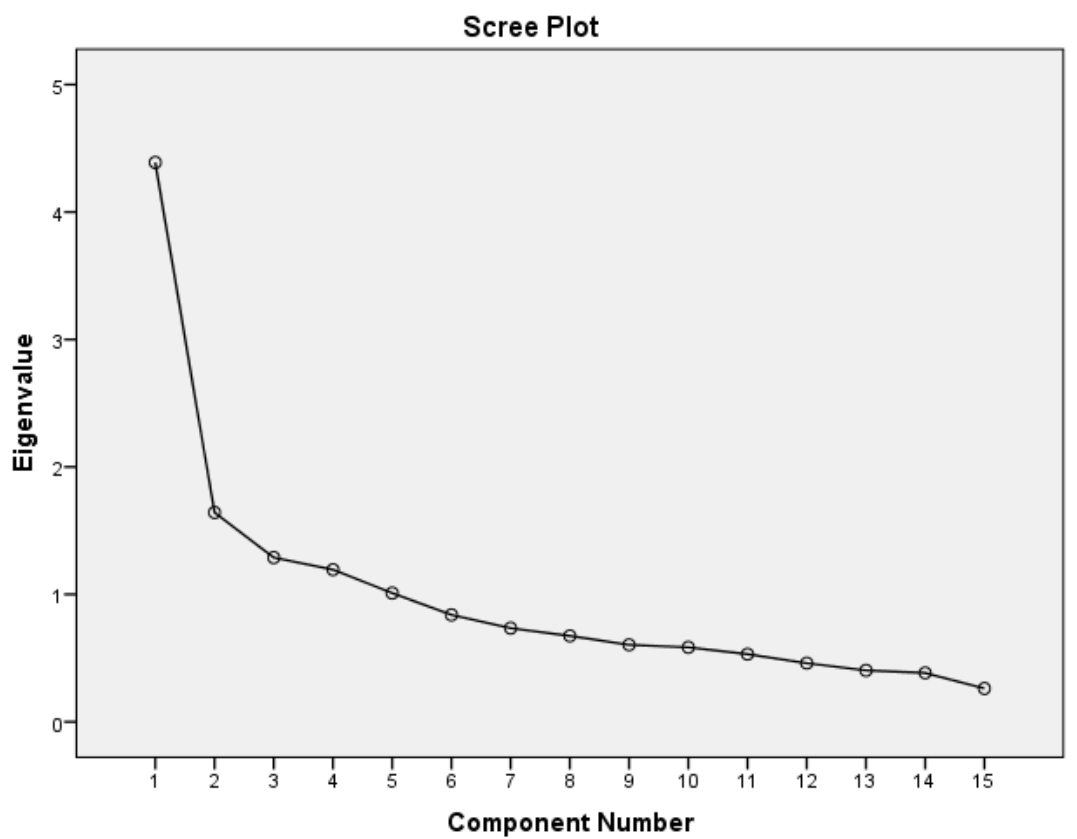

Figure 1. Scree plot

The scree plot is a graph of the eigenvalues against all variables. If can be seen that the curve begin to flatten after 5 factors. From factor 6 , the eigenvalue is less than one. Thus only first 5 variables are retained above eigenvalue of 1 .

\section{Communalities}

Table 5. Communalities

\begin{tabular}{clcc}
\hline Sl. No & Factors & Initial & Extraction \\
\hline & & & \\
1 & Self-preferred (X1) & 1.000 & .651 \\
2 & Like the specialization (X2) & 1.000 & .761 \\
3 & Job opportunities (X3) & 1.000 & .623 \\
4 & Feel now as inappropriate (X4) & 1.000 & .721 \\
5 & College oriented to choose (X5) & 1.000 & .471 \\
6 & Easy to study (X6) & 1.000 & .741 \\
7 & HRM and Accounting appropriate for females (X7) & 1.000 & .620 \\
8 & Marketing needs more field work and travel (X8) & 1.000 & .523 \\
9 & Marketing jobs are for expatriates (X9) & 1.000 & .633 \\
10 & Students with high CGPA deserve HRM or Accounting (X10) & .712 \\
11 & Marketing is inferior to other specializations (X11) & 1.000 & .648 \\
12 & Family advice (X12) & 1.000 & .000 \\
13 & Friend's and seniors advice (X13) & 1.000 & .685 \\
14 & Evaluated the possibilities myself (X14) & 1.000 & .537 \\
15 & More jobs available for marketing (X15) & 1.000 & .549 \\
\end{tabular}

Principal component analysis works on the initial assumption that all variance is common. Therefore before extraction the communalities are all 1 . The communalities in the column labeled extraction reflect the common variance in the data structure. $65.1 \%$ of the variance is associated with factor 1 (self-preferred) is common or shared variance. Similarly $76.1 \%$ of the variance is associated with the second factor (Liking of specialization) is common or shared variance. Another way to look at these communalities is in terms of the proportion of variance explained by the underlying factors. After extraction some of the factors are discarded. The amount of variance in each variable that can be explained by the retained factors is represented by the communalities after extraction. 
Table 6. Component matrix

\begin{tabular}{|c|c|c|c|c|c|}
\hline Factors & 1 & 2 & 3 & 4 & 5 \\
\hline Feel now as inappropriate (X4) & .728 & -.395 & & & \\
\hline Like the specialization $(\mathrm{X} 2)$ & .725 & -.437 & & & \\
\hline Self-preferred (X1) & .709 & & & & \\
\hline Job opportunities (X3) & .652 & -.353 & & & \\
\hline College oriented to choose (X5) & 608 & & & & \\
\hline Evaluated the possibilities myself (X14) & .601 & & & & \\
\hline Marketing needs more field work and travel (X8) & .497 & & & .313 & \\
\hline Marketing jobs are for expatriates (X9) & .352 & .600 & & .308 & \\
\hline Marketing is inferior to other specializations (X11) & .415 & .494 & & & -.454 \\
\hline High CGPA deserves HRM or Accounting (X10) & .502 & & .670 & & \\
\hline HRM and Accounting appropriate for females (X7) & .486 & & .613 & & \\
\hline More jobs available for marketing (X15) & & & -.439 & .314 & \\
\hline Family advice (X12) & .400 & & & -.650 & \\
\hline Friend's and seniors advice (X13) & .494 & & & -.497 & \\
\hline Easy to study (X6) & .387 & & & & .669 \\
\hline
\end{tabular}

The component matrix is shown in table no.6 before rotation. This matrix contains the loadings of each factor into each factor. All the loadings less than 0.32 are suppressed in the output so there are blank spaces for many of the loadings. The table no. 6 shows the loadings (extracted values of each item under 5 variables) of 15 variables on the 5 factors extracted. The higher the absolute value of the loading, the more the factor contributes to variable. 5 variables are extracted wherein the 15 items are divided into 5 variables according to the most important items with similar response in component 1 and component 2,3,4, and 5.

At this stage SPSS has extracted five factors. By Kaiser's criterion, five factors are extracted and is proved accurate. It is accurate when the average communalities is greater than 0.6. The average of the communalities is found by adding the communalities divided by the number of factors $(9.52 / 15=0.63)$. Thus on both the grounds Kaiser's rule is accurate.

\section{Factor Rotation}

Table 7. Rotated Component Matrix ${ }^{a}$

\begin{tabular}{|c|c|c|c|c|c|}
\hline & & & mpo & & \\
\hline & 1 & 2 & 3 & 4 & 5 \\
\hline Like the specialization $(\mathrm{X} 2)$ & .829 & & & & \\
\hline Feel now as inappropriate (X4) & .829 & & & & \\
\hline Self-preferred (X1) & .753 & & & & \\
\hline Job opportunities (X3) & .662 & & & & \\
\hline College oriented to choose (X5) & .623 & & & & \\
\hline Family advice (X12) & & .802 & & & \\
\hline Friend's and seniors advice (X13) & & .758 & & & \\
\hline Evaluated the possibilities myself (X14) & & .593 & & & \\
\hline Marketing is inferior to other specializations (X11) & & & .759 & & \\
\hline Marketing jobs are for expatriates (X9) & & & 676 & & \\
\hline Marketing needs more field work and travel (X8) & & & 638 & & \\
\hline High CGPA deserves HRM or Accounting (X10) & & & & .809 & \\
\hline HRM and Accounting appropriate for females (X7) & & & & .747 & \\
\hline Easy to study (X6) & & & & & .826 \\
\hline More jobs available for marketing (X15) & & & & & .556 \\
\hline Extraction Method: Principal Component Analysis. & & & & & \\
\hline Rotation Method: Varimax with Kaiser Normalization. & & & & & \\
\hline otation converged in 5 iterations. & & & & & \\
\hline
\end{tabular}

Table 7 shows the rotated component matrix or the rotate factor matrix in factor analysis. This is a matrix of the factor loadings for each variable onto each factor after rotation. The idea of rotation is the reduce the number of factor on which the variables under investigation have high loadings. The variables that load highly on factor 1 $(\mathrm{X} 2, \mathrm{X} 4, \mathrm{X} 1, \mathrm{X} 3, \mathrm{X} 5)$ relate to preference and dissonance post choice. Therefore, it is labeled as Preference and dissonance post choice. The three variables that load heavily on factor 2 (X12, X13, X14) relate to peer influence and is labelled as Self and Peer influence. The variables that loads heavily on factor 3 is related to variables (X11, X9, X8) and are labelled as Nature of marketing specialization. Similarly, the variables that load heavily on factor $4(\mathrm{X} 10, \mathrm{X} 7)$ contain components of appropriateness of specialization to specific gender and therefore labelled as Gender and specialization choice. Finally, the variables that load heavily on factor 5 (X6, $\mathrm{X} 16)$ relates to ease in pursuing and career prospects and therefore it is labelled as Convenience and career. 
Thus this analysis reveals that the initial questionnaire is composed of five sub-scales: Preference and dissonance post choice, Self and Peer influence, Nature of marketing specialization, Gender and specialization choice, Convenience and career. This model is shown in figure 2.

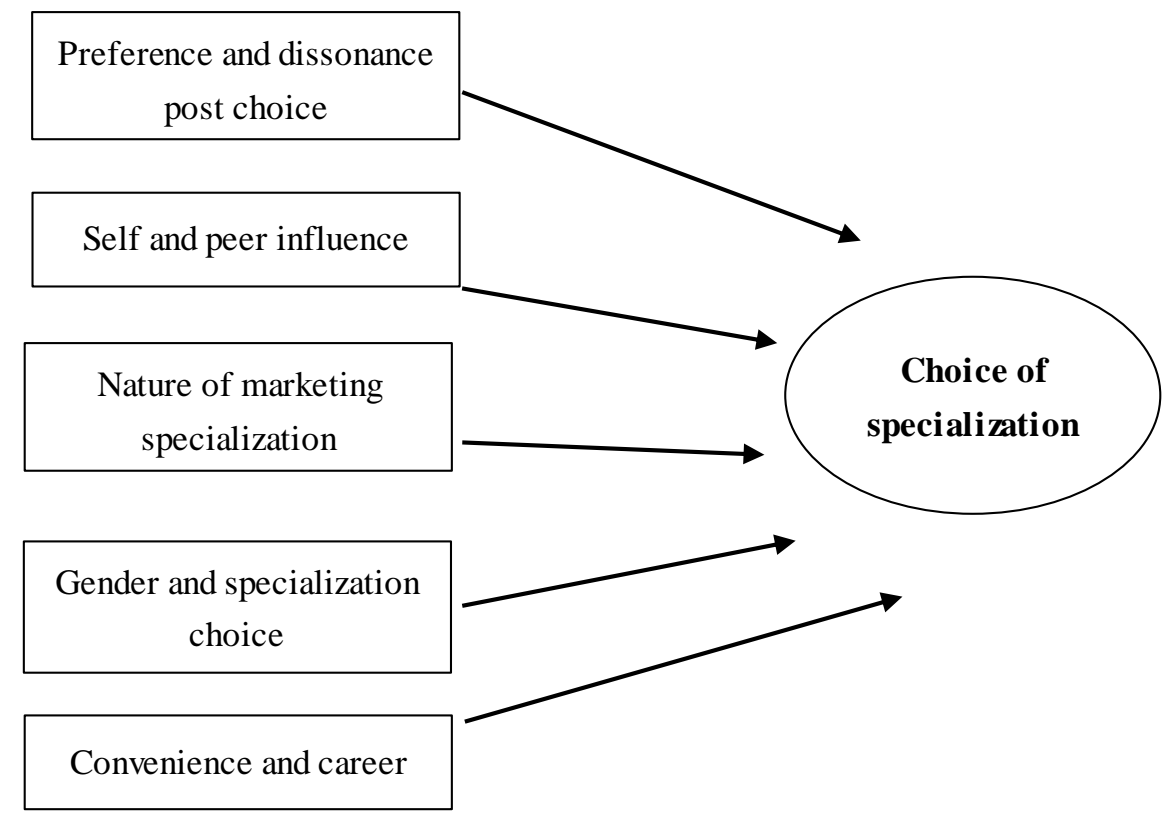

Figure 2. Student's perception variables

\section{Regression Analysis}

Multiple regression method is used to identify the impact of variables on the choice of specialization by the students. This helps to analyse the impact of independent variables over the dependent variable. From the study results it is clear that $63 \%$ of the existing students advice HRM specialization as first choice to their juniors, $32 \%$ of the students advice Accounting and only 5\% of the students advice Marketing specialization to their juniors. The output of multiple regression analysis revealed that College orientation (X5) (P < 0.001) in choosing the specialization is the significant factor that influences the students to advice their juniors. The other factors are insignificant in advising the first choice of specialization.

Table 8. Coefficients (first choice)

\begin{tabular}{|c|c|c|c|c|c|}
\hline \multirow[t]{2}{*}{ Model } & \multicolumn{2}{|c|}{$\begin{array}{l}\text { Unstandardized } \\
\text { Coefficients }\end{array}$} & \multirow{2}{*}{$\begin{array}{c}\begin{array}{c}\text { Standardized } \\
\text { Coefficients }\end{array} \\
\text { Beta } \\
\end{array}$} & \multirow[t]{2}{*}{$\mathrm{t}$} & \multirow[t]{2}{*}{ Sig. } \\
\hline & $\mathrm{B}$ & Std. Error & & & \\
\hline (Constant) & 1.839 & .266 & & 6.924 & .000 \\
\hline Self-preferred (X1) & -.031 & .057 & -.062 & -.555 & .579 \\
\hline Like the specialization (X2) & .005 & .061 & .011 & .091 & .928 \\
\hline Job opportunities (X3) & .013 & .053 & .026 & .248 & .805 \\
\hline Feel now as inappropriate (X4) & .066 & .062 & .126 & 1.062 & .290 \\
\hline College oriented to choose (X5) & -.154 & .045 & -.323 & -3.425 & .001 \\
\hline Easy to study (X6) & .031 & .047 & .059 & .666 & .506 \\
\hline HRM and Accounting appropriate for females (X7) & -.023 & .041 & -.052 & -.550 & .583 \\
\hline Marketing needs more field work and travel (X8) & .012 & .047 & .022 & .246 & .806 \\
\hline Marketing jobs are for expatriates (X9) & -.040 & .047 & -.079 & -.854 & .394 \\
\hline $\begin{array}{l}\text { Students with high CGPA deserve HRM or } \\
\text { Accounting (X10) }\end{array}$ & .001 & .042 & .003 & .031 & .976 \\
\hline Marketing is inferior to other specializations (X11) & .053 & .048 & .101 & 1.101 & .273 \\
\hline Family advice (X12) & .006 & .040 & .013 & .147 & .883 \\
\hline Friend's and seniors advice (X13) & .026 & .040 & .062 & .655 & .514 \\
\hline Evaluated the possibilities myself (X14) & -.008 & .048 & -.015 & -.159 & .874 \\
\hline More jobs available for marketing (X15) & .011 & .039 & .023 & .271 & .786 \\
\hline
\end{tabular}

The descriptive statistics results showed that $53 \%$ of the current students advice Accounting as their second choice to the juniors. $28 \%$ of the students advice HRM specialization and $19 \%$ of the students advice marketing as their second choice to their juniors. The regression results showed that there is no significant factor that influences the students to advice the second choice of specialization to their juniors. 
The statistical analysis showed that $76 \%$ of the students suggest Marketing as third choice for their juniors, $15 \%$ of the students advice Accounting as a third choice and $9 \%$ of the students advice HRM specialization. The main factor that influences the current students for suggesting the third choice as specialization is that HRM and Accounting specializations are appropriate for females (X7). The factor (X7) is found to be significant ( $\mathrm{p}<$ 0.017). Other factors are found to be insignificant in advising as third choice to the junior students.

Table 9. Coefficients (Third choice)

\begin{tabular}{|c|c|c|c|c|c|}
\hline \multirow{2}{*}{ Model } & \multicolumn{2}{|c|}{$\begin{array}{l}\text { Unstandardized } \\
\text { Coefficients }\end{array}$} & \multirow{2}{*}{$\begin{array}{c}\text { Standardized } \\
\text { Coefficients }\end{array}$} & \multirow[t]{2}{*}{$\mathrm{t}$} & \multirow[t]{2}{*}{ Sig. } \\
\hline & $\bar{B}$ & Std. Error & & & \\
\hline (Constant) & 2.008 & .356 & & 5.640 & .000 \\
\hline Self-preferred (X1) & .006 & .076 & .009 & .081 & .936 \\
\hline Like the specialization $\quad(\mathrm{X} 2)$ & -.001 & .081 & -.002 & -.017 & .986 \\
\hline Job opportunities (X3) & .105 & .071 & .148 & 1.476 & .142 \\
\hline Feel now as inappropriate (X4) & -.119 & .083 & -.166 & -1.439 & .152 \\
\hline College oriented to choose (X5) & .076 & .060 & .116 & 1.263 & .209 \\
\hline Easy to study (X6) & -.092 & .063 & -.125 & -1.452 & .149 \\
\hline HRM and Accounting appropriate for females (X7) & .134 & .055 & .223 & 2.423 & .017 \\
\hline Marketing needs more field work and travel (X8) & -.014 & .063 & -.020 & -.229 & .819 \\
\hline Marketing jobs are for expatriates (X9) & -.006 & .063 & -.009 & -.097 & .923 \\
\hline $\begin{array}{l}\text { Students with high CGPA deserve HRM or Accounting } \\
\text { (X10) }\end{array}$ & .064 & 057 & .108 & 1.136 & .258 \\
\hline Marketing is inferior to other specializations (X11) & -.011 & .065 & -.015 & -.167 & .868 \\
\hline Family advice (X12) & -.060 & .054 & -.099 & -1.114 & .267 \\
\hline Friend's and seniors advice (X13) & -.019 & .054 & -.032 & -.345 & .730 \\
\hline Evaluated the possibilities myself (X14) & .052 & .065 & .076 & .805 & .422 \\
\hline More jobs available for marketing (X15) & .035 & .053 & .055 & .666 & .507 \\
\hline ependent Variable: Choice 3 & & & & & \\
\hline
\end{tabular}

\section{Findings of the study}

1. The most important variable that influences the students' choice of specialization is the variable 'Liking and preference of specialization' (X2) with the highest mean of 4.18.

2. It is concluded that the first five variables (X1, X2, X3, X4 and X5) constitutes $63.5 \%$ of the cumulative variance. These variables greatly influence the choice of specialization.

3. The variables that load highly on factor $1(\mathrm{X} 2, \mathrm{X} 4, \mathrm{X} 1, \mathrm{X} 3, \mathrm{X} 5)$ relate to preference and dissonance post choice which is labeled as Preference and dissonance post choice. The three variables that load heavily on factor 2 (X12, X13, X14) relate to peer influence and is labeled as Self and Peer influence. The variables that loads heavily on factor 3 is related to variables (X11, X9, X8) and is labeled as Nature of marketing specialization. Similarly, the variables that load heavily on factor 4 (X10, X7) contain components of appropriateness of specialization to specific gender and therefore labeled as Gender and specialization choice. Finally, the variables that load heavily on factor 5 (X6, X16) relate to ease in pursuing and career prospects and therefore it is labeled as Convenience and career.

4. College orientation on specialisation (X5) is the significant factor that influences the students to advice their juniors to make the first choice of specialisation viz. HRM (63\%), Accounting (32\%) and Marketing (5\%).

5. $53 \%$ of the students advice Accounting as their second choice to the juniors. $28 \%$ of the students advice HRM specialization and $19 \%$ of the students advice marketing as their second choice. There is no significant factor that influences to advice the second choice of specialization to their juniors.

6. The variable "HRM and Accounting specializations are appropriate for females" (X7) is the significant factor that influences the students to advice their juniors to make the third choice of specialisation viz. Marketing (76\%), Accounting (15\%) and HRM (9\%).

\section{Conclusion}

The paper attempted to see the fundamental variable that influences the choice of specialization by business students in relationship with other factors. The study derives that College orientation to the students and the negative perception that Accounting and HRM specialization are mainly for females are the major factors that influences the choice of specialization. Mismatch of the personality and lack of interest in the subject is dangerous, and could end up into disastrous results in terms of student dissatisfaction, demotivation, lack of productivity leading to increased drop outs and career failure. It is important for parents, educators and advisors to help prospective students make an informed career decisions so as to fulfill student's career expectations. 
Students should be given the right orientation to choose their specialization according to their interests and abilities. Students lack proper awareness and orientation regarding Marketing specialization. The recommendations derived through this study will help the student community to opt the correct choice of specialization. Therefore, each specialization offered will have a composite batch of students with high score, average score, fair score, poor score. The negative perception prevailing in the minds of the student community with regard to marketing specialization will have to be eradicated and enable students to approach all specializations without any prejudice.

\section{Recommendations}

1. It is recommended that the orientation provided to the students by the college shall be on a level playing field with equal emphasis being placed on all specializations offered and build an administrative requirement on offering specialization.

2. Specialization should be offered based on personal traits of the students.

3. Advisors can take a major role in counseling and conduct a test to analyse their traits and guide the students to choose the right specialization.

4. Selection of specialization is a dominant decision and hence students must be given support from professional instructors and industry experts to orient the students on the latest emerging trends and its impact. This will direct the students in the right perspective for making better career choices.

\section{Future Direction of the Study}

In view of the importance of the topic and its implications on the future success of the students in their career, it is strongly recommended to make further studies to investigate the factors influencing the career choice of the students; and use the findings in the student counselling and support centers to orient the students about their career choice criteria and options. Further research based on this research can be conducted to determine whether the students' career expectations were met during the course of their studies and thereafter, once they are employed. The model developed through this research can also be applied in other Colleges of Technology in Oman. A longitudinal study can be carried out to analyse the change in perception regarding the choice of specialisation.

\section{References}

Abrahams, F., Jano, R., \& Van Lill, B. (2015), Factors influencing the career choice of undergraduate students at a historically disadvantaged South African University. Industry and Higher Education, 29(30), 209-219. https://doi.org/10.5367/ihe.2015.0253

Alberts, C., Mbalo, N. L., \& Ackermann, C. J. (2003). 'Adolescents' Perceptions of the Relevance of Domains of Identity Formation: A South African Cross-Cultural Study'. Journal of Youth and Adolescence, 32(3), 169-184. https://doi.org/10.1023/A:1022591302909

Al-Lawati, E. H. (2017) Exploration of Entrepreneurial Marketing Orientation model among SMEs in Oman: International Journal of Economics \& Management Sciences, 6(3), 1-6. https://doi.org/10.4172/2162-6359.1000432

Bennell, P. (2004). Teacher motivation and incentives in sub-Saharan Africa and Asia. Unpublished Research Report. Retrieved from http://eldis.org/fulltext/dfidtea.pdf

Carson, D. J. (1990). Some exploratory models for assessing small firm's marketing performance: A qualitative approach. European Journal of Marketing, 24, 1-51. https://doi.org/10.1108/03090569010006056

Cosmas, V. J. (2010). Relationship between personality traits and career choice among secondary school students in Tanzania (Unpublished Master's thesis). University of Dar es Salaam, Tanzania

Datu, J. A. (2012). Personality traits and parenting style as predictive factors of career choice. Academic Research International, 3(1), 118-124.

Edwards, K., \& Quinter, M. (2012). Factors Influencing Students Career Choices among Secondary School students in Kisumu Municipality, Kenya. Journal of Emerging Trends in Educational Research and Policy Studies, 2(2), 81-87

Ferry, N. M. (2006). Factors Influencing Career Choices of Adolescents and Young Adults in Rural Pennsylvania. Journal of Extension, 44(3).

Gouvias, D. (1998). The relation between unequal access to higher education and labour market structure: the case of Greece. British Journal of Sociology of Education, 19(3), 305-333. 
https://doi.org/10.1080/0142569980190303

Kidd, J. M. (2009). Career counselling. In G, Hugh \& P, Maury. (Eds.), Handbook of Career Studies, (pp.97-113). London: SAGE Publication Inc.

Krejcie, R. V., \& Morgan, D. W. (1970). Determining sample size for research activities. Educational and psychological measurement, 30(3), 607-610. https://doi.org/10.1177/001316447003000308

Livanos, I., \& Pouliakas, K. (2009). The gender wage gap as a function of educational degree choices in an occupationally segragated country. IZA Discussion paper No 4636.

Mashige, K. P., \& Oduntan, O. A. (2011). 'Factors influencing South African optometry students in choosing their career and institution of Learning'. The South African Optometrist, 70(1) 21-28. https://doi.org/10.4102/aveh.v70i1.90

Mbilinyi, C. (2012). Determinants of career decision making among secondary school students in Tanzania (Unpublished Master's Dissertation). University of Dar es Salaam, Dar es Salaam

McCorkle, D., Payan, J., Reardon, J., \& Kling, N. (2007). Perceptions and Reality: Creativity in the Marketing Classroom. Journal of Marketing Education, 29(3), 254-261. https://doi.org/10.1177/0273475307306892

Mubiana, P. B. (2010). Career maturity, career knowledge, and self-knowledge among psychology honours students: An exploration study (Master Thesis), University of Pretoria, Pretoria.

Nwalo, K. I. N., \& Issa, A. O. (2008). Factors affecting the career choice of undergraduates in Nigerian library and information science schools. African Journal of Library, Archives \& Information Science, 18(1), 23-32

Olamide, S. O., \& Olawaiye, S. O. (2013). The factors determining the choice of career among secondary school students. The International Journal of Engineering and Science, 2(6), 33-44.

Paglin, M., \& Rufolo, A. (1990). Heterogenous human capital, occupational choice and male-female earnings differences. Journal of Labor Economics, 8(1), part 1,123-144. https://doi.org/10.1086/298239

Psacharopoulos, G., \& Papakonstantinou, G. (2005). The real university cost in a "free" higher education country. Economics of Education Review, 24(1),103-108. https://doi.org/10.1016/j.econedurev.2004.01.003

Rebecca, J., Kimongo, K., Nyaga, K., \& Benard, M. (2016) Relationship between Personality Types and Career Choices of Undergraduate Students: A Case of Moi University. Kenya Journal of Education and Practice, 7(3), 102-112

Saiti, A., \& Prokopiadou, G. (2008). The demand for higher education in Greece. Journal of Further and Higher Education, 32(3), 285-296. https://doi.org/10.1080/03098770802221080

Shertzer, B. (2003). Stone, Shelly C Fundamentals of Counseling: 2nd Edition.

Sianou-Kyrgiou, E., \& Tsiplakides, I. (2009). Choice and social class of medical school students in Greece. British Journal of Sociology of Education, 30(6), 727-740. https://doi.org/10.1080/01425690903235276

Sianou-Kyrgiou, E. (2010). Stratification in Higher education, choice and social inequalities in Greece. Higher Education Quarterly, 64(1), 22-40. https://doi.org/10.1111/j.1468-2273.2009.00427.x

Tsakloglou, P., \& Antoninis, M. (1999). On the distribution impact of public education: evidence from Greece. Economics of Education Review, 18(4), 439-452. https://doi.org/10.1016/S0272-7757(99)00018-7

Wang, H. H., \& Fwu, B. J. (2001). Why teach? The motivation and commitment of graduate students of a teacher education program in a research university. Practical National Science Council, 11 (4), 390-400.

World Economic Outlook, October 2016 and January 2017 Update, IMF and Regional Economic Outlook, Middle East and Central Asia, October, 2016.

Zafar, B. (2009). College major choice and the gender gap. FRB of New York Staff Report, no 364. https://doi.org/10.2139/ssrn.1348219

Zhang, W. (2007). Why IS: 'Understanding undergraduate students' intentions to choose an Information Systems major'. Journal of Information Systems Education, 18(4), 447-458.

\section{Copyrights}

Copyright for this article is retained by the author(s), with first publication rights granted to the journal.

This is an open-access article distributed under the terms and conditions of the Creative Commons Attribution license (http://creativecommons.org/licenses/by/4.0/). 